\title{
Effects of whole wheat dilution $v$. substitution on coccidiosis in broiler chickens
}

\author{
M. J. Banfield and J. M. Forbes* \\ Centre for Animal Sciences, LIBA, School of Biology, University of Leeds, Leeds LS2 9JT, UK \\ (Received 21 September 2000 - Revised 25 January 2001 - Accepted 13 February 2001)
}

\begin{abstract}
To test the hypothesis that inclusion of whole cereals in the diet of broiler chickens reduces the severity of a coccidial infection, the effects were investigated, in birds infected with Eimeria acervulina, of feeding a complete pelleted control food, the control food diluted with whole wheat $(400 \mathrm{~g} / \mathrm{kg})$, or a diet in which ground wheat in the pellets was substituted with whole wheat $(400 \mathrm{~g} / \mathrm{kg})$ so as to achieve the same composition as the control diet. In the weeks prior to and after infection, (days 14-20 and days 21-27), no significant differences in performance were observed between birds fed the complete pellet and substituted feeds. Birds fed the diluted feeds had significantly lower gains per unit of feed and numerically lower weight gains than the birds fed the control and substituted feeds during this period. No significant differences in performance were observed between treatments from days 28-34. Diluting feeds with whole wheat $(400 \mathrm{~g} / \mathrm{kg})$ significantly increased ileal digesta viscosity levels, compared with feeding the control and substituted feeds in birds dissected on day 21, although no significant differences in digesta viscosity levels were observed in birds dissected on day 35 . Whole wheat feeding, either by dilution or substitution, significantly increased gizzard sizes in birds dissected on day 21 and day 35. Neither dilution nor substitution of feeds with whole wheat $(400 \mathrm{~g} / \mathrm{kg})$ significantly affected the level of an Eimeria acervulina infection, as measured by daily and total faecal oocyst yields.
\end{abstract}

\section{Broiler chickens: Growth: Whole wheat: Coccidiosis}

Coccidiosis is a disease of the intestinal tract caused by protozoan intestinal parasites of the genus Eimeria (Long, 1984). Current prevention and control relies predominantly on the use of chemotherapeutic drugs added directly to the feeds. However, some resistance to all coccidiostats in current use has been recently reported (Chapman, 1997). Global economic losses are currently estimated to be at least US\$800 million/year, accounted for by prophylactic in-feed medication, therapy and control of outbreaks of disease, and financial losses due to morbidity and mortality (Williams, 1998).

The use of whole wheat in feeds has been observed to reduce the severity of a coccidial infection in chickens. RB Cumming (unpublished results) observed that birds fed high-fibre diets, and whole wheat in a choice-feeding situation, and infected with a combination of Eimeria tenella - Eimeria acervulina - and Eimeria maxima (70:20:10), excreted far fewer coccidial oocysts than those fed low-fibre diets. He tentatively suggested that an increase in gizzard size and grinding action, brought about by an increase in fibre levels and/or the whole grain structure of the wheat, might be responsible for the physical destruction of the oocysts prior to reaching their sites of infection. This theory was supported by later work in which oocyst yields were negatively correlated with gizzard size, and observations that feeding insoluble grit, either with a conventional pellet, or with whole grains in a free-choice-feeding situation, reduced faecal oocyst yields (RB Cumming, unpublished results). However, Waldenstedt (1998), investigating the effects of whole wheat inclusion in broiler feeds $(300 \mathrm{~g} / \mathrm{kg})$, with or without access to grit, observed no significant differences in faecal oocyst yields, lesion scores, or performance in birds infected with Eimeria tenella or Eimeria maxima, although birds given feed containing whole wheat and infected with Eimeria maxima did display numerically $(P<0.09)$ higher weight gains than those fed the standard feeds.

The use of whole grains in broiler feeds is common practice in Northern Europe and has been comprehensively reviewed by Forbes \& Covasa (1995). Chickens possess the

\footnotetext{
Abbreviation: FCE, Feed conversion efficiency.

* Corresponding author: Professor J. M. Forbes, fax +44 113 2333066, email j.m.forbes@leeds.ac.uk
} 
ability to efficiently process and digest whole grains (Sturkie, 1965), primarily due to a significant increase in gizzard size, needed to grind the whole grains before passing down to the small intestine (Rose et al. 1986; JB Cumming, unpublished results). Whole wheat can be included in a starter ration at up to $400 \mathrm{~g} / \mathrm{kg}$ without affecting performance (Mcintosh et al. 1962; Kiiskinen, 1996; JB Langhout, JB Schutte and HB Perdok, unpublished results; C Polat, N Senkoylu, H Akyurek, HE Samli, G Uour and Y Agyuziu, unpublished results).

The work mentioned earlier used whole grains in the feeds as a replacement for the existing cereal fraction. Relatively little work has been done to establish the effects of simple dilution of a broiler feed with whole grains, compared with an undiluted feed, although Bennett et al. (1995) observed that up to $300 \mathrm{~g}$ whole or crumbled wheat/ $\mathrm{kg}$ dilution of complete feeds did not affect weight gain in male or female broilers, although food conversion efficiency (FCE, weight gain per unit of feed, $\mathrm{kg} / \mathrm{kg}$ ) was significantly worse in the cockerels fed the diluted feeds. A similar experiment, reported by M Covasa and JM Forbes (unpublished results), investigated diluting broiler feeds with $340 \mathrm{~g}$ whole or ground wheat $/ \mathrm{kg}$, compared with birds fed undiluted commercial mash, and observed no significant differences in performance between the different treatment groups. The physical form of the wheat had no effect on performance in either sex. Kiiskinen (1996) diluted starter and grower feeds with up to $400 \mathrm{~g}$ whole grain wheat and barley/kg and reported that whole grain

Table 1. Diet composition

\begin{tabular}{|c|c|c|c|}
\hline Ingredients (g/kg) & $\begin{array}{l}\text { Control } \\
\text { feed }\end{array}$ & $\begin{array}{l}\text { Diluted } \\
\text { feed }\end{array}$ & $\begin{array}{l}\text { Substituted } \\
\text { feed }\end{array}$ \\
\hline Whole wheat & 0.0 & $400 \cdot 0$ & $400 \cdot 0$ \\
\hline Ground wheat & $400 \cdot 0$ & $240 \cdot 0$ & 0.0 \\
\hline Maize & $200 \cdot 0$ & $120 \cdot 0$ & $200 \cdot 0$ \\
\hline Maize gluten meal $(607 \mathrm{~g} / \mathrm{kg})$ & $50 \cdot 0$ & $30 \cdot 0$ & $50 \cdot 0$ \\
\hline Soybean meal $(467 \mathrm{~g} / \mathrm{kg})$ & $100 \cdot 0$ & $60 \cdot 0$ & $100 \cdot 0$ \\
\hline Casein $(880 \mathrm{~g} / \mathrm{kg})$ & $50 \cdot 0$ & $30 \cdot 0$ & $50 \cdot 0$ \\
\hline Meat and bone meal $(584 \mathrm{~g} / \mathrm{kg})$ & $30 \cdot 0$ & $18 \cdot 0$ & $30 \cdot 0$ \\
\hline Tapioca $(650 \mathrm{~g} / \mathrm{kg})$ & $50 \cdot 0$ & $30 \cdot 0$ & $50 \cdot 0$ \\
\hline Maize meal & $21 \cdot 8$ & $13 \cdot 1$ & $21 \cdot 8$ \\
\hline Animal fat & $30 \cdot 0$ & $18 \cdot 0$ & $30 \cdot 0$ \\
\hline Soya oil-maize oil & $20 \cdot 0$ & $12 \cdot 0$ & $20 \cdot 0$ \\
\hline Cellulose (powdered) & $10 \cdot 0$ & $6 \cdot 0$ & $10 \cdot 0$ \\
\hline Premix (maize) & $10 \cdot 0$ & $6 \cdot 0$ & $10 \cdot 0$ \\
\hline Salt $(\mathrm{NaCl})$ & 1.0 & 0.6 & 1.0 \\
\hline Calcium carbonate & $9 \cdot 0$ & 5.4 & $9 \cdot 0$ \\
\hline Monocalcium phosphate & $8 \cdot 0$ & $4 \cdot 8$ & $8 \cdot 0$ \\
\hline $\mathrm{NaHCO}_{3}$ & 3.0 & 1.8 & 3.0 \\
\hline $\mathrm{KHCO}_{3}$ & 3.0 & $1 \cdot 8$ & 3.0 \\
\hline L-lysine HCL & $2 \cdot 7$ & 1.6 & $2 \cdot 7$ \\
\hline DL-methionine & $1 \cdot 0$ & 0.6 & $1 \cdot 0$ \\
\hline L-threonine & 0.5 & 0.3 & 0.5 \\
\hline \multicolumn{4}{|l|}{ Calculated analysis } \\
\hline Protein $(\mathrm{g} / \mathrm{kg})$ & 209 & 178 & 209 \\
\hline Calcium (g/kg) & 7 & 6 & 7 \\
\hline Phosphorus (g/kg) & 6 & 4 & 6 \\
\hline Available methionine $(\mathrm{g} / \mathrm{kg})$ & 5 & 4 & 5 \\
\hline $\begin{array}{l}\text { Available methionine }+ \\
\text { cystine }(\mathrm{g} / \mathrm{kg})\end{array}$ & 8 & 7 & 8 \\
\hline$M E_{n}(M J / k g)$ & $13 \cdot 5$ & $13 \cdot 3$ & $13 \cdot 5$ \\
\hline
\end{tabular}

ME, metabolisable energy. dilution of a starter feed is suitable for broiler production during the growing period.

In previous work, we observed no significant reductions in faecal oocyst yields in broiler chickens fed feeds diluted with $200 \mathrm{~g}$ whole wheat $/ \mathrm{kg}$, compared with birds offered feeds diluted with $200 \mathrm{~g}$ finely ground wheat $/ \mathrm{kg}$ (Banfield et al. 1998). Furthermore, the substitution of 200 and $400 \mathrm{~g}$ whole wheat $/ \mathrm{kg}$ broiler feed has been observed to significantly increase faecal oocyst yields, while significantly reducing bird performance, in birds infected with Eimeria acervulina (Banfield et al. 1999). The objective of the present experiment was to compare the effects of feeding a complete pelleted feed, the same feed diluted with $400 \mathrm{~g}$ whole wheat $/ \mathrm{kg}$, and $400 \mathrm{~g}$ whole wheat $/ \mathrm{kg}$ and a balancer pellet, on bird performance and faecal oocyst yields in birds infected with Eimeria acervulina.

\section{Materials and methods}

\section{Animals and housing}

Female 1-d-old broiler chicks of a commercial strain (Ross, $n$ 100) were obtained from Mayfield Hatcheries, Rossendale, Lancs., UK. The chicks were placed as a group on wood shavings in a single-floor pen and remained so until day 8. Temperature was kept constant at $33^{\circ} \mathrm{C}$ and continuous lighting was applied during this period. A commercial starter crumb and water were provided ad libitum. On day 8, forty-eight were randomly selected, weighed and placed in pairs into twenty-four identical cages $(43 \mathrm{~cm} \times 43 \mathrm{~cm} \times 43 \mathrm{~cm})$ with wire-mesh floors in a single room. Final feeds were introduced on day 14 (Table 1), at which point the experiment was started. From day 8 the room temperature was reduced by $2^{\circ} \mathrm{C}$ every day to reach a temperature of $21^{\circ} \mathrm{C}$ on day 14 . This remained constant $\left( \pm 1^{\circ} \mathrm{C}\right)$ for the rest of the experiment. The lighting cycle was set at $23 \mathrm{~h}$ light $-1 \mathrm{~h}$ dark (dark from 00.00 to 01.00 hours), which was maintained for the rest of the experiment. Fresh feed and water were provided daily at 09.00 hours and each was available ad libitum. At 09.00 hours on day 21, one bird per cage received 150000 sporulated Eimeria acervulina (Weybridge strain) oocysts in $1 \mathrm{ml}$ tap water, via an oral gavage, directly into the crop. A clean polythene sheet was placed daily under each cage for the rest of the experiment to collect the day's faeces for oocyst analysis. The remaining bird per cage was killed by an injection of triple-strength barbiturates $(1 \mathrm{ml} / \mathrm{kg}$ body weight) into the wing vein, dissected and gastrointestinal variables and digesta viscosity measured. On day 35 the remaining birds were killed and dissected.

\section{Feeds}

The chicks were fed a commercial starter crumb $(240 \mathrm{~g} / \mathrm{kg}$ crude protein, $12.5 \mathrm{MJ} / \mathrm{kg}$ metabolisable energy) from day 1-8. From day 8-34 the birds received either: (1) a complete pelleted diet (control feed); (2) a feed consisting of the complete pellet diluted with $400 \mathrm{~g}$ whole wheat $/ \mathrm{kg}$ (diluted feed, likely to be unbalanced and deficient in protein, at least at the start of the experiment); (3) a feed composed of a balancer pellet, essentially the control feed 
with the cereal component reduced, so that when the $400 \mathrm{~g}$ whole wheat $/ \mathrm{kg}$ was added, the mixture was nutritionally identical to the control feed (substituted feed, same overall composition as control feed). Whole wheat was introduced gradually to the feeds, starting with $100 \mathrm{~g}$ whole wheat $/ \mathrm{kg}$, $300 \mathrm{~g}$ ground wheat $/ \mathrm{kg}$ on day 8 , with the whole wheat fraction increasing by $100 \mathrm{~g} / \mathrm{kg}$ every $2 \mathrm{~d}$ to reach a final level of $400 \mathrm{~g} / \mathrm{kg}$ by day 14 (Table 1). The final feeds, introduced from day 8 did not contain any anti-coccidial products. The feeds were produced by the ILOB-TNO Institute, Wageningen, The Netherlands.

Whole wheat $(116 \mathrm{~g} / \mathrm{kg}$ crude protein, $13 \cdot 1 \mathrm{MJ} / \mathrm{kg}$ metabolisable energy) was also obtained from the ILOBTNO Institute, and was taken from a single batch to form both the ground wheat constituents of the pelleted feeds, as well as any whole wheat fractions added to the pelleted feeds. The wheat had a mean in vitro viscosity of $16.6 \mathrm{mPa} \cdot \mathrm{s}$ (Nordos, Trouw Nutrition Nederland, Putten, The Netherlands). From day 8-34 feeds were prepared on a daily basis. The whole wheat was added to, and mixed with, the pellets by hand for each individual cage. Feed refusals for the previous week were passed by rubbing through a sieve to crumble the pellets and separate the whole grains from the commercial pellet, and each component was then weighed to calculate whole grain and pellet refusals. Feed intake, and the proportion of whole wheat intake, was calculated on a weekly basis.

\section{Eimeria acervulina oocyst inoculum, dose preparation and analysis}

Eimeria acervulina (Weybridge strain) oocysts, maintained and passaged at the School of Biology, The University of Leeds, UK, by periodic passage through young chickens, were used to infect the birds. Inoculum doses were prepared according to the method set out by Shirley (1995).

Faeces (excreta) were collected on the day of infection to ascertain whether the birds displayed any prior signs of infection. Subsequently, faeces were collected daily on clean polythene sheets placed beneath the experimental cages. All faeces were carefully examined for coccidial oocysts using a McMaster's counting chamber (Merck Eurolab, Lutterworth, UK) and the method described by Long \& Rowell (1958). Total daily faecal oocysts excreted/ bird per d were calculated.

\section{Ileal digesta viscosity analysis}

Digesta samples were taken from the ileum immediately after killing, homogenised, centrifuged at $13000 \mathrm{rpm}$ for $10 \mathrm{~min}$ in a micro-centrifuge and analysed at $40^{\circ} \mathrm{C}$ using a Brookfield viscometer (Brookfield Engineering Laboratories Inc, Cambridge, MA, USA). Duplicate samples were analysed, corrected for temperature variations, and the mean values calculated.

\section{Statistical analysis}

Data were analysed using the General Linear Model in Minitab 12 (Minitab for Windows, Statistical software, release 12.0; Minitab Ltd, Coventry, UK) with the treatments (control $v$. diluted $v$. substituted) as the factors in a randomised model. As the daily oocyst yields were not normally distributed they were transformed $\left(\log _{10}(x+1)\right)$ to create a normal distribution before being analysed. Means were separated using the least significant difference test, with significance set at $P<0.05$.

Table 2. Effects of dietary dilution and substitution with whole wheat on total feed intake ( $\mathrm{g} / \mathrm{bird}$ per d), average daily pellet and whole-wheat intake $(\mathrm{g} /$ bird per $\mathrm{d})$, and pellet and wheat intake expressed as a proportion of total feed intake in broiler chickens infected with Eimeria acervulina*

(Mean values with their standard errors for eight birds per dietary group)

\begin{tabular}{|c|c|c|c|c|c|}
\hline Treatment & Control & Diluted & Substituted & SEM & $\begin{array}{c}\text { Statistical significance of } \\
\text { effect of treatment: } P\end{array}$ \\
\hline \multicolumn{6}{|c|}{ Feed intake $(\mathrm{g} / \mathrm{d})$} \\
\hline Day $14-20$ & $81 \cdot 2$ & 83.6 & $77 \cdot 7$ & 1.51 & 0.289 \\
\hline Day 21-27 & $98 \cdot 6$ & $106 \cdot 5$ & $94 \cdot 0$ & $2 \cdot 26$ & 0.067 \\
\hline Day $28-34$ & $140 \cdot 9$ & $158 \cdot 0$ & $148 \cdot 6$ & 3.04 & 0.055 \\
\hline \multicolumn{6}{|c|}{ Pellet intake $(\mathrm{g} / \mathrm{d})$} \\
\hline Day $14-20$ & $81 \cdot 2^{a}$ & $50 \cdot 3^{b}$ & $46 \cdot 1^{\mathrm{b}}$ & 3.41 & $<0.001$ \\
\hline Day $21-27$ & $98 \cdot 6^{\mathrm{a}}$ & $67 \cdot 6^{\mathrm{b}}$ & $56 \cdot 3^{c}$ & 4.00 & $<0.001$ \\
\hline Day 28-34 & $140 \cdot 9^{\mathrm{a}}$ & $95 \cdot 3^{\mathrm{b}}$ & $88 \cdot 2^{b}$ & $5 \cdot 85$ & $<0.001$ \\
\hline \multicolumn{6}{|c|}{ Pellet intake ( $\mathrm{g} / \mathrm{kg}$ food) } \\
\hline Day $14-20$ & $1000^{\mathrm{a}}$ & $602^{\mathrm{b}}$ & $593^{b}$ & $38 \cdot 3$ & $<0.001$ \\
\hline Day $21-27$ & $1000^{\mathrm{a}}$ & $636^{\mathrm{b}}$ & $599^{b}$ & 37.9 & $<0.001$ \\
\hline Day 28-34 & $1000^{a}$ & $602^{b}$ & $594^{\mathrm{b}}$ & $39 \cdot 6$ & $<0.001$ \\
\hline \multicolumn{6}{|c|}{ Whole-wheat intake (g/d) } \\
\hline Day $14-20$ & - & $33 \cdot 3$ & 31.6 & 0.79 & 0.301 \\
\hline Day 21-27 & - & $39 \cdot 0$ & $37 \cdot 7$ & 1.37 & 0.666 \\
\hline Day 28-34 & - & $63 \cdot 1$ & $60 \cdot 4$ & 1.00 & 0.187 \\
\hline \multicolumn{6}{|c|}{ Whole-wheat intake (g/kg food) } \\
\hline Day $14-20$ & - & $398^{\mathrm{a}}$ & $407^{\mathrm{b}}$ & 1.80 & 0.007 \\
\hline Day $21-27$ & - & $364^{\mathrm{a}}$ & $401^{\mathrm{b}}$ & $7 \cdot 60$ & 0.009 \\
\hline Day 28-34 & - & $398^{\mathrm{a}}$ & $406^{\mathrm{b}}$ & 1.98 & 0.036 \\
\hline
\end{tabular}

\footnotetext{
a,b,c Mean values within the same row with unlike superscript letters were significantly different $(P \leq 0.05)$
}

* For details of diets and procedures, see Table 1 and p. 90. 


\section{Results}

\section{Feed intake}

No significant differences in total feed intakes were observed between treatment groups in the week prior to infection, days 14-20 (Table 2). In the weeks following infection, days 21-27 and days 28-34, the birds fed the diluted feeds had numerically higher total feed intakes ( $P=0.067$ and $P=0.055$ respectively) than those fed the control and substitution feeds.

Birds fed on the control feed had significantly higher pellet intakes than the birds fed the diluted and substituted feeds for all 3 weeks of the experiment (Table 2). Birds fed the diluted diet had significantly higher daily pellet intakes than the birds fed the substituted feed in the week after infection, days 2127 , and numerically higher intakes from days 14-20, and days 28-34. When assessed as a percentage of total feed intake a similar pattern was seen, with control birds again having significantly higher daily pellet intakes than the birds fed the diluted and substituted feeds. Prior to infection no difference in proportional pellet intake was seen between the birds fed the diluted and substituted feeds, but in the following 2 weeks the birds offered the diluted feeds ate a significantly higher proportion of pellets than the birds on the substituted feeds, although the difference between the diluted and substituted fed birds was very small.

Actual whole wheat intakes did not differ significantly between the birds fed the diluted or substituted feeds at any point during the experiment (Table 2). However, when assessed as a percentage of total feed intake, the birds fed the diluted feeds ate a significantly lower percentage of whole wheat than the birds fed the substituted feeds throughout the experiment, although the differences between the treatments were small (Table 2).

\section{Live weight and weight gain}

No significant differences in live weight were observed between treatment groups on day 7. By day 14 the birds fed the diluted feed had significantly lower live weights than those fed the control and substitution feeds (Table 3 ). On day 21 , the day of infection, the birds fed the diluted feed were still significantly lighter than the control birds, but not the birds fed the substitution feed. Daily weight gains during this period, days 14-20, reflected this, although the differences observed were not quite significant. Daily weight gains were again lower in the diluted-feed treatment in the week following infection, days 21-27, and birds fed the diluted feed again had significantly lower live weights on day 28 than the birds fed the control and substituted feeds. No significant differences in daily weight gains were seen from days 28-34, although the birds fed the dilution and substitution feeds gained numerically more weight than the controls, with the result that live weight on day 35 did not differ significantly between treatment groups.

\section{Feed conversion efficiency}

The birds fed diluted feeds had significantly lower feed conversion efficiency (FCE) than the control birds and the birds fed the substituted feeds during the weeks prior to and the week after infection (days 14-20, days 21-27) (Table 3). No significant differences in FCE were observed between the birds fed the substituted feed and the controls during this period. From days 28-34 no significant differences in FCE were seen between treatment groups, although, as from days 14-27, the birds fed the diluted feed tended to convert their feed less efficiently than the control and substituted fed birds.

Table 3. Effects of dietary dilution and substitution with whole wheat on live weight $(\mathrm{g})$, average daily weight gain (g/bird per d), feed intake $(\mathrm{g} /$ bird per $\mathrm{d})$, and feed conversion efficiency in broiler chickens infected with Eimeria acervulina* (Mean values with their standard errors for eight birds per dietary group)

\begin{tabular}{|c|c|c|c|c|c|}
\hline Treatment & Control & Diluted & Substituted & SEM & $\begin{array}{c}\text { Statistical significance of } \\
\text { effect of treatment: } P\end{array}$ \\
\hline \multicolumn{6}{|l|}{ Live weight (g) } \\
\hline Day 7 & $133 \cdot 3$ & $132 \cdot 0$ & $126 \cdot 9$ & 1.96 & 0.395 \\
\hline Day 14 & $305 \cdot 1^{\mathrm{a}}$ & $286 \cdot 5^{\mathrm{b}}$ & $305 \cdot 9^{a}$ & $3 \cdot 16$ & 0.011 \\
\hline Day 21 & $661 \cdot 9^{\mathrm{a}}$ & $602 \cdot 2^{\mathrm{b}}$ & $636 \cdot 7^{\mathrm{ab}}$ & $9 \cdot 41$ & 0.026 \\
\hline Day 28 & $1013 \cdot 6^{a}$ & $897 \cdot 9^{b}$ & $979 \cdot 8^{a}$ & 14.47 & 0.001 \\
\hline Day 35 & $1513 \cdot 0$ & $1421 \cdot 6$ & $1510 \cdot 0$ & $22 \cdot 01$ & $0 \cdot 158$ \\
\hline \multicolumn{6}{|c|}{ Weight gain (g/d) } \\
\hline Day $7-13$ & $24 \cdot 6^{a}$ & $22 \cdot 1^{b}$ & $25 \cdot 6^{a}$ & 0.44 & 0.001 \\
\hline Day 14-20 & $51 \cdot 0$ & $45 \cdot 1$ & $47 \cdot 3$ & 1.05 & 0.062 \\
\hline Day 21-27 & $50 \cdot 3$ & $42 \cdot 2$ & $49 \cdot 0$ & 1.57 & 0.074 \\
\hline Day 28-34 & $71 \cdot 3$ & 74.8 & $75 \cdot 8$ & 2.08 & 0.680 \\
\hline \multicolumn{6}{|c|}{ FCE (g gain/g food) } \\
\hline Day 14-20 & $0.63^{a}$ & $0.54^{b}$ & $0.61^{a}$ & 0.009 & $<0.001$ \\
\hline Day 21-27 & $0.51^{a}$ & $0.40^{\mathrm{b}}$ & $0.52^{a}$ & 0.016 & 0.001 \\
\hline Day 28-34 & 0.50 & 0.47 & 0.51 & 0.008 & 0.313 \\
\hline
\end{tabular}

FCE, Feed conversion efficiency.

a,b Mean values within the same row with unlike superscript letters were significantly different $(P \leq 0.05)$

${ }^{*}$ For details of diets and procedures, see Table 1 and p. 90. 
Table 4. Effects of dietary dilution and substitution with whole wheat on ileal digesta viscosities (mPa.s), and relative gastrointestinal organ weights $(\mathrm{g} / \mathrm{kg}$ empty-body weight) and lengths ( $\mathrm{m} / \mathrm{kg}$ empty-body weight) in broiler chickens infected with Eimeria acervulina

(Mean values with their standard errors for eight birds per dietary group)

\begin{tabular}{|c|c|c|c|c|c|}
\hline Treatment & Control & Diluted & Substituted & SEM & $\begin{array}{l}\text { Statistical significance of } \\
\text { effect of treatment: } P\end{array}$ \\
\hline \multicolumn{6}{|l|}{ Day 21} \\
\hline Ileal viscosity & $4 \cdot 51^{\mathrm{a}}$ & $8 \cdot 68^{\mathrm{b}}$ & $4 \cdot 00^{\mathrm{a}}$ & 0.558 & $<0.001$ \\
\hline Gizzard weight & $20^{\mathrm{a}}$ & $30^{\mathrm{b}}$ & $30^{\mathrm{b}}$ & $1 \cdot 2$ & $<0.001$ \\
\hline Jejunum length & $0.78^{\mathrm{a}}$ & $0.99^{c}$ & $0.89^{b}$ & 0.026 & 0.001 \\
\hline \multicolumn{6}{|l|}{ Day 35} \\
\hline Ileal viscosity & 3.41 & $4 \cdot 28$ & 5.04 & 0.369 & 0.212 \\
\hline Gizzard weight & $12^{a}$ & $22^{\mathrm{b}}$ & $21^{\mathrm{b}}$ & 1.0 & $<0.001$ \\
\hline Jejunum length & $0.53^{\mathrm{ab}}$ & $0.57^{\mathrm{a}}$ & $0.52^{\mathrm{b}}$ & 0.10 & 0.040 \\
\hline lleum length & $0.52^{\mathrm{ab}}$ & $0.56^{a}$ & $0.48^{\mathrm{b}}$ & 0.012 & 0.035 \\
\hline Caecum length & $0 \cdot 12^{\mathrm{a}}$ & $0 \cdot 14^{\mathrm{b}}$ & $0 \cdot 12^{\mathrm{a}}$ & 0.003 & 0.012 \\
\hline
\end{tabular}

${ }^{a, b}$ Mean values within the same row with unlike superscript letters were significantly different $(P \leq 0.05)$.

\section{Ileal digesta viscosity levels and gastrointestinal organ sizes}

On day 21 the birds fed the diluted feed had significantly higher ileal digesta viscosity levels than the birds fed the control and substituted feeds, while on day 35 no significant differences in viscosity were observed between the treatment groups (Table 4).

Birds given the feeds containing whole wheat had significantly heavier gizzards than control on day 21 and day 35. No significant differences in gizzard weight were observed between the birds fed the diluted or substituted feeds on either day 21 or day 35 (Table 4). On day 21 jejunum lengths of the birds fed the diluted feed were significantly longer than those found in the birds fed the control and substituted feeds. By day 35 the birds fed the diluted feeds had significantly longer jejuna and ilea than those fed the substituted feed and numerically longer ilea and jejuna than those fed the control feed. Birds fed the diluted feed also had significantly longer caeca than those fed the control and substituted feeds at this stage (Table 4).

\section{Faecal oocyst yields}

Faeces collected on the day of infection, day 21, did not contain any oocysts and so the birds were assumed to be initially free of infection. No significant differences in daily faecal oocyst yields were seen between the treatment groups at any point during the experiment, and no significant differences in total faecal oocyst yields, days 22-34, between treatment groups were observed (Fig. 1).

\section{Discussion}

Neither the dilution nor substitution of whole wheat $(400 \mathrm{~g} / \mathrm{kg})$ into the diet of broiler chickens had a significant effect on the output of Eimeria acervulina oocysts following an oral infection. As expected, there was

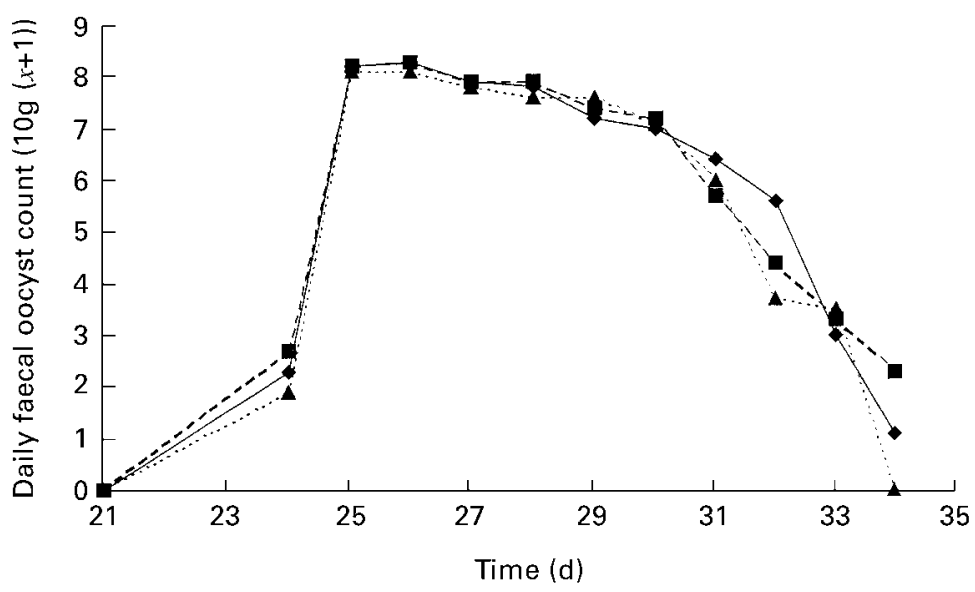

Fig. 1. Effects of dietary dilution and substitution with whole wheat on daily log $10(x+1)$ faecal oocyst yields in broiler chicks infected with Eimeria acervulina. For details of diets and procedures, see Table 1 and p. 90 . Values are means for eight birds per dietary group. $\bullet$, control; $\mathbf{\square}$; diluted diet; $\boldsymbol{\Lambda}$, substituted diet (note that from days 21-27 the lines for control and diluted are contiguous. SEM between days 25 and 30 for the log 10 counts ranged from 0.06 to 0.10 . 
no effect of substitution of whole wheat for most of the cereal portion of the diet, whereas dilution significantly reduced weight gain and FCE, particularly during the first part of the experiment.

\section{Nutritional aspects of whole wheat}

The results from days $14-20$, in the healthy broiler chicks before infection, suggest that the birds were capable of utilising levels of up to $400 \mathrm{~g}$ whole wheat $/ \mathrm{kg}$ as efficiently as ground wheat in their feeds, demonstrated by the lack of significant differences in performance between the birds fed the control and substituted feeds. The significantly heavier gizzards observed in the whole wheat-fed birds killed on day 21 have presumably developed in response to the increased grinding activity needed to process the whole grains prior to digestion further along the gastrointestinal tract, as previously observed (see p. 89).

However, when feeds in the current experiment were diluted with $400 \mathrm{~g}$ whole wheat $/ \mathrm{kg}$, significant reductions in live weight on day 21 and FCE from days 14-20 were seen compared with the birds fed the control or substituted feeds. The reductions are presumably attributable to a decrease in the concentrations of nutrients (Table 1). Another factor that may have affected the performance of the birds fed the diluted feeds was the higher ileal digesta viscosity levels observed in these birds, compared with the birds fed the control and substituted feeds, dissected on day 21. An increase in digesta viscosity has been linked to the levels of NSP found in the feed. In wheat, the NSP associated with anti-nutritive properties have been established as being the water-soluble fraction of the arabinoxylans (pentosans) (Choct \& Annison, 1990, 1992a,b). The higher levels of NSP present in the feed diluted with whole wheat, brought about by the higher overall levels of wheat in the feed, have previously been reported to impair bird performance by increasing digesta viscosity, reducing nutrient digestion and absorption in the small intestines (Thomson \& Dietschy, 1977; Johnson \& Gee, 1981; Choct $\&$ Annison, 1992a,b). Furthermore, the NSP themselves are also subject to microbial fermentation, which has been associated with the majority of the impact of offering feeds containing high levels of NSP on bird performance (Annison, 1993; Choct et al. 1996; Langhout, 1998). Therefore, a combination of a reduction in dietary nutrients, increased ileal digesta viscosity levels, and changes in the microbial populations of the gastrointestinal tract are suggested to be responsible for the reductions in performance seen in the birds fed the diluted feeds from days $14-20$.

During the recovery period, days $28-42$, the birds fed the diluted feeds appeared to have overcome the effects of the reduced nutritional value of their diets, increasing their weight gains and feed intakes, resulting in improved FCE during this period. As a result, no significant differences in performance were observed between the dietary treatment groups during this period. The compensation in growth in the birds offered the diluted feeds during this period was enough so that final body weights at the end of the experiment, day 35, were not significantly different between the treatment groups. These improvements in performance appear to be due to the significant changes observed in the gastrointestinal organs of the birds dissected on day 35 . Once again the whole wheat-fed birds displayed significantly heavier gizzards than the birds fed feeds containing ground wheat, as was observed on day 21. However, the birds fed the diluted feed also had significantly longer jejuna, ilea and caeca than the birds fed the substituted feed, and numerically longer jejuna and ilea, and significantly longer caeca, than the controls. Whether these changes were a direct response to the nutrient dilution of the diet, or an indirect response to the increased ileal digesta viscosity levels observed in the birds fed the diluted feed and dissected on day 21, is unclear, particularly as no significant differences in ileal digesta viscosity levels were observed in the birds dissected on day 35 .

\section{Infection aspects of whole wheat}

Diluting or substituting whole wheat $(400 \mathrm{~g} / \mathrm{kg})$ into broiler feeds, compared with offering a complete pellet, had no effect on the level of infection, as measured by faecal oocyst yields. RB Cumming (unpublished results) has previously reported that feeding whole wheat in a choicefeeding situation significantly reduced faecal oocyst yields in birds infected with Eimeria tenella - Eimeria acervulina - Eimeria maxima (70:20:10) suggesting that the significant increases in gizzard size, and subsequent grinding activity, were responsible for the physical destruction of the coccidial oocysts prior to reaching their sites of infection. However, despite the significant increases in gizzard size observed both prior to and after infection in the whole wheat-fed birds in the current experiment, no significant effect on faecal oocyst yields was observed. Similar results have previously been reported by ourselves and others, in which diluting the feed of birds infected with Eimeria acervulina with either whole or ground wheat (Banfield et al. 1998, 1999) or feeding whole wheat with a balancer pellet, compared with a complete pellet to birds infected with Eimeria tenella and Eimeria maxima (Waldenstedt, 1998), resulted in no significant differences in bird performance or faecal oocyst yields.

The lack of effect of whole wheat feeding, in comparison with the work of RB Cumming (unpublished results) could be due to a number of factors: birds were placed on the experimental diets on day 8 and infected on day 21 which, in the experience of RB Cumming (unpublished results), is too short a period of receiving whole wheat to gain full benefit, particularly as the percentage of whole wheat was only slowly increasing. In his work, all the grain has been given unground, while in the present experiment some of the grain was given in the compound food and was thus not contributing to gizzard development.

Our diets contained significant amounts of maize and it has been reported that birds on maize-based diets reacted less severely to an Eimeria tenella infection than wheatbased diets (Williams, 1992). A very high oocyst challenge, 150000 oocysts per bird, was used here, in comparison with that used by Cumming, and this might have overridden any protective effect of whole wheat. RB Cumming (unpublished results) has said of whole-cereal feeding that: 'This biological control measure of the chicken needs to be 
kept in perspective. We have seen in a number of experiments that the resistance of a 'normal' active gizzard can be overwhelmed by a massive coccidiosis challenge' and (RB Cumming, unpublished results): 'This defence or resistance from a normal, active gizzard is not absolute but relative'.

\section{Conclusion}

The inclusion of up to $400 \mathrm{~g}$ whole wheat $/ \mathrm{kg}$, as a replacement for ground wheat in the diet, did not affect either healthy bird performance, or the performance of birds infected with Eimeria acervulina, apparently because of the efficient processing of the whole wheat in the enlarged gizzards observed in the whole wheat-fed birds. Diluting feeds with $400 \mathrm{~g}$ whole wheat $/ \mathrm{kg}$ did, however, significantly reduce bird performance in the weeks prior to and after infection, presumably due to the dilution of the nutrients in the feed, and/or the increase in ileal digesta viscosity caused by feeding higher levels of wheat in the diet.

Neither whole wheat dilution of, or substitution into, the feeds significantly affected the level of Eimeria acervulina infection, as measured by faecal oocyst yields. Resistance to infection with Eimeria acervulina was not increased by the feeding of whole cereals in this experiment which suggests that whole wheat addition to the diet of broiler chickens, as commonly practised in Northern Europe, provides no control of coccidiosis.

\section{Acknowledgements}

MRB was in receipt of a Postgraduate Studentship from MAFF and the authors gratefully acknowledge additional financial support provided by the Yorkshire Agricultural Society, and Dalgety Agriculture, Bristol, UK.

\section{References}

Annison G (1993) The role of wheat non-starch polysaccharides in broiler nutrition. Australian Journal of Agricultural Research 44, 405-422.

Banfield MJ, Kwakkel RP, Groenveld M, ten Doeschate RAHM \& Forbes JM (1999) Effects of whole wheat substitution in broiler diets and viscosity on a coccidial infection in broilers. British Poultry Science 40, S58-S60.

Banfield MJ, ten Doeschate RAHM \& Forbes JM (1998) The effect of whole wheat and heat stress on a coccidial infection in broiler chickens. British Poultry Science 39, S25.

Bennett CD, Classen HL \& Riddell C (1995) Live performance and health of broiler chickens fed diets diluted with whole or crumbled wheat. Canadian Journal of Animal Science 75, 611614.

Chapman HD (1997) Biochemical, genetic and applied aspects of drug resistance in eimeria parasites of the fowl. Avian Pathology 26, 221-244.

Choct M \& Annison G (1990) Anti-nutritive effect of wheat pentosans in broiler diets. British Poultry Science 31, 811-821.

Choct M \& Annison G (1992a) Anti-nutritive effect of wheat pentosans in broiler chickens: Roles of viscosity and gut microflora. British Poultry Science 33, 821-834.

Choct M \& Annison G (1992b) The inhibition of nutrient digestion by wheat pentosans. British Journal of Nutrition $\mathbf{6 7}$, 123-132.

Choct M, Hughes RJ, Wang J, Bedford MR, Morgan AJ \& Annison G (1996) Increased small intestinal fermentation is partly responsible for the anti-nutritive activity of non-starch polysaccharides in chickens. British Poultry Science 37, 609-621.

Forbes JM \& Covasa M (1995) Application of diet selection by poultry with particular reference to whole cereals. World's Poultry Science Journal 51, 149-165.

Johnson IT \& Gee JM (1981) Effect of gel-forming gums on the intestinal unstirred layer and sugar transport in vitro. Gut $\mathbf{2 2}$, 398-403.

Kiiskinen T (1996) Feeding whole grain with pelleted diets to growing broiler chickens. Agricultural and Feed Science in Finland 5, 167-175.

Langhout DJ (1998) The role of intestinal flora as affected by nonstarch polysaccharides in broiler chickens. $\mathrm{PhD}$ Thesis, Wageningen Agricultural University.

Long PL (1984) Coccidiosis control: Past, present and future. British Poultry Science 25, 3-18.

Long PL \& Rowell JG (1958) Counting oocysts of chicken coccidia. Laboratory Practice 7, 515-518.

McIntosh JI, Slinger SJ, Sibbald IR \& Ashton GC (1962) The effects of three physical forms of wheat on the weight gains and feed efficiencies of pullets from hatching to fifteen weeks of age. Poultry Science 41, 438-445.

Rose SP, Burnetti A \& Elmajeed RA (1986) Factors affecting the diet selection of choice-fed broilers. British Poultry Science 27, 215-224.

Shirley MW (1995) Eimeria and isospora, eimeria species and strains of chickens. In European Commission: Eur 16602 Guidelines on Techniques in Coccidiosis Research, pp. 1-23. Luxembourg: Office for Official Publications of the European Communities.

Sturkie PD (1965) Avian Physiology. London: Balliere, Tindall and Cassell.

Thomson ABR \& Dietschy JM (1977) Derivations of the equations that described the effects of unstirred water layers on the kinetic parameters of active transport processes in the intestine. Journal of Theoretical Biology 64, 277-294.

Waldenstedt L (1998) Coccidial and clostridial infections in broiler chickens - influence of diet composition. PhD Thesis, Swedish University of Agricultural Sciences, Uppsala.

Williams RB (1992) Differences between the anticoccidial potencies of monensin in maize-based or wheat-based chicken diets. Veterinary Research Communications 16, 147-152.

Williams RB (1998) Epidemiological aspects of the use of live anticoccidial vaccines for chickens. International Journal for Parasitology 28, 1089-1098. 